Article

\title{
Genome-Wide Identification of DNA Binding with One Finger (Dof) Gene Family in Tartary Buckwheat (Fagopyrum tataricum) and Analysis of Its Expression Pattern after Exogenous Hormone Stimulation
}

\author{
Jing Li ${ }^{1}$, Yuchuan Zhang ${ }^{1}$, Lei Xu ${ }^{1}$, Chenyang Wang ${ }^{1}$, Yan Luo ${ }^{1}$, Shan Feng ${ }^{2}$, Yuhao Yuan ${ }^{1}$, Qinghua Yang ${ }^{1}$ \\ and Baili Feng ${ }^{1, *(\mathbb{D})}$
}

check for updates

Citation: Li, J.; Zhang, Y.; Xu, L.; Wang, C.; Luo, Y.; Feng, S.; Yuan, Y.; Yang, Q.; Feng, B. Genome-Wide Identification of DNA Binding with One Finger (Dof) Gene Family in Tartary Buckwheat (Fagopyrum tataricum) and Analysis of Its Expression Pattern after Exogenous Hormone Stimulation. Biology 2022, 11, 173. https://doi.org/10.3390/ biology11020173

Academic Editor: Daniel G. Peterson

Received: 28 December 2021 Accepted: 18 January 2022

Published: 21 January 2022

Publisher's Note: MDPI stays neutral with regard to jurisdictional claims in published maps and institutional affiliations.

Copyright: (C) 2022 by the authors. Licensee MDPI, Basel, Switzerland. This article is an open access article distributed under the terms and conditions of the Creative Commons Attribution (CC BY) license (https:// creativecommons.org/licenses/by/ $4.0 /)$.
1 State Key Laboratory of Crop Stress Biology for Arid Areas, College of Agronomy, Northwest A\&F University, Xianyang 712000, China; lijing1993@nwafu.edu.cn (J.L.); zhangyuchuan@nwafu.edu.cn (Y.Z.); 2020055040@nwafu.edu.cn (L.X.); wcy410223@163.com (C.W.); 1994lyyl@nwsuaf.edu.cn (Y.L.); yuanyuhao@nwafu.edu.cn (Y.Y.); 2016060037@nwsuaf.edu.cn (Q.Y.)

2 School of Mathematics and Statistics, Northwestern Polytechnical University, Xi'an 710129, China; fengshan1912@mail.nwpu.edu.cn

* Correspondence: fengbaili@nwsuaf.edu.cn

Simple Summary: A number of studies have demonstrated that DNA binding with one finger (Dof) proteins are involved in multiple biological processes. In the present study, Dof genes or proteins in Tartary buckwheat (FtDofs) were systematically analysed, including their physical properties, phylogenetic relationships, structure, motif composition, cis-acting elements present in promoter regions, chromosomal distribution, gene duplication events, syntenic relationships, expression patterns in different tissues and different fruit developmental stages and responses to exogenous hormone stimulation. The results indicated that the expansion of FtDofs was mainly due to segmental duplication. The tissue-specific expression patterns of FtDofs and their positive responses to exogenous hormone stimulation suggest that they play important roles in the growth and development of Tartary buckwheat as well as in the adaptation to environmental changes. Collectively, this study lays a foundation for further exploration of the function of FtDof genes in Tartary buckwheat.

Abstract: DNA binding with one finger (Dof) proteins have been proven to be involved in multiple biological processes. However, genome-wide identification of the Dof gene family has not been reported for Tartary buckwheat (Fagopyrum tataricum). In this study, 35 FtDof proteins were identified, and they could be divided into nine phylogenetic subgroups. Proteins within the same subgroup had similar gene structure and motif composition. Moreover, abundant cis-acting elements were present in the promoter regions of FtDof genes. Segmental duplication was the primary driving force for the evolution of the FtDof gene family. Synteny analysis indicated that Tartary buckwheat was closer to dicotyledons, and more orthologous Dof genes existed among them. The expression pattern of FtDofs in different tissues and at different fruit developmental stages varied. Different tissues contained several genes that were specifically expressed. FtDof expression was mainly upregulated under methyl jasmonate treatment and downregulated under other hormone treatments. Taken together, FtDofs may play important roles in the growth and development of Tartary buckwheat and in response to abiotic and biotic stresses. Therefore, the genome-wide identification and expression pattern analysis of the Tartary buckwheat Dof gene family lays a foundation for further exploration of the functional characteristics of FtDofs in the future.

Keywords: Tartary buckwheat; Dof; motif; cis-acting elements; synteny analysis; hormone 


\section{Introduction}

Transcription factors (TFs) participate in recruiting and recognizing specific DNA sequence elements in the promoter region of genes to regulate the spatiotemporal expression of target genes and further control or influence several biological processes [1]. DNA binding with one finger (Dof) proteins are a subfamily of the zinc finger protein family; they are ubiquitous but plant-specific (they have not been found in other eukaryotes, such as yeast or animals) [2,3]. Dof proteins are usually made up of 200-400 amino acids, and they have a highly conserved Dof domain composed of 50-52 amino acids at the N-terminus [2], a nuclear localisation signal and a transcriptional regulatory domain at the C-terminus, which varies greatly [4]. The Dof domain has a Cys2/Cys2 zinc finger structure, which can bind to the AAAG cis-element in the promoter region of the target gene and is considered as a bifunctional domain that plays key roles in DNA-binding and protein-protein interaction activities $[2,5,6]$.

The first Dof protein was cloned from maize leaves (ZmDof1) and preliminarily considered as a DNA-binding protein [7]. Dof genes have recently been identified in numerous plants with the completion of genome sequencing of plant species. The number of Dof genes greatly varies among different species; for example, there are 36 in Arabidopsis thaliana [8], 30 in rice (Oryza sativa) [8], 26 in barley (Hordeum vulgare) [9], 46 in maize (Zea mays) [10], 28 in sorghum (Sorghum bicolor) [11], 34 in tomato (Solanum lycopersicum) [12] and 96 in wheat (Triticum aestivum) [13]. Furthermore, a number of studies have evidenced the unique role of Dof proteins in multiple biological processes, including tissue differentiation, seed development and regulation of metabolism [14], vascular tissue development [15], stomatal maturation and functioning [16], flowering time [17,18], pollen maturation [19], seed germination [20,21], endosperm development [22], carbon and nitrogen metabolism [23] and responses to phytohormones [24-27], as well as biotic and abiotic stresses [28-30]. These findings proved that Dof proteins play crucial roles in the growth and development of plants, and these TFs also play a role in the response to abiotic and biotic stresses. However, to the best of our knowledge, genome-wide identification and relevant studies of the Dof gene family have not been reported for Tartary buckwheat.

Tartary buckwheat (Fagopyrum tataricum) is an edible and medicinal crop originating from China. The grains of Tartary buckwheat are gluten-free and rich in bioflavonoids, which have many important biological functions; therefore, the Tartary buckwheat grain has been praised as one of the 21st century's green foods [31,32]. In our previous research, we found that the leaves and flowers of Tartary buckwheat are also rich in flavonoids, indicating its potential application in pharmaceutical and food industries [33,34]. However, the weak research foundation for Tartary buckwheat makes it difficult to meet the growing demand for in-depth development and utilisation [35]. A high-quality, chromosomescale Tartary buckwheat genome was recently reported [36], thus making it possible to systematically study some gene families with important functions on the basis of the whole genome. In the present study, the characteristics, evolution and expression of Dof genes in Tartary buckwheat were comprehensively analysed to lay a foundation for subsequent studies on the function of FtDof genes.

\section{Materials and Methods}

\subsection{Identification of Dof Family Genes in Tartary buckwheat}

A total of 36 Dof proteins of $A$. thaliana obtained from the TAIR database (https: / / www. arabidopsis.org/, accessed on 1 September 2020) were used for BLASTP searches to retrieve possible FtDofs in the Tartary buckwheat genome (http:/ / www.mbkbase.org/Pinku1/, accessed on 1 September 2020), with e-value $\leq 1 \times 10^{-10}$ and score value $\geq 100$, to identify the Dof family genes in Tartary buckwheat [37]. Then, the hidden Markov model profile of the Dof domain (PF02701) acquired from the Pfam database (http://pfam.xfam.org/, accessed on 1 September 2020) was used to retrieve FtDofs from the Tartary buckwheat genome by using HMMER3.3 with default parameters. Furthermore, the putative sequences were submitted to the Conserved Domain Database (CDD, https: / / www.ncbi.nlm.nih.gov / 
cdd, accessed on 13 October 2020), SMART (http: / / smart.embl-heidelberg.de/, accessed on 2 September 2020) and Pfam (accessed on 15 October 2020) for verifying the existence of the Dof core sequences. Subcellular localisation was predicted by CELLO (http: / / cello.life.nctu. edu.tw /, accessed on 5 September 2020). Protein molecular weight (Mw) and theoretical isoelectric point $(p I)$ were computed via Expasy (https://web.expasy.org/compute_pi/, accessed on 5 September 2020).

\subsection{Phylogenetic Analyses and Classification of FtDof Family Members}

The phylogenetic tree of the Dof proteins from A. thaliana and Tartary buckwheat was constructed using the maximum likelihood (ML) method with MEGA X (version 10.0.4, Mega Limited, Auckland, New Zealand) [38]. The protein sequences of FtDofs and AtDofs were first aligned using MUSCLE with default settings [39]. Then, the best model of the ML method was calculated using MEGA X. Finally, the JTT + G + I + F model was chosen to construct the phylogenetic tree. The bootstrap value was set to 1000 , and all positions with less than $80 \%$ site coverage were eliminated. Then, the $F t$ Dofs were grouped in accordance with the classification of AtDofs [8].

\subsection{Sequence Characteristic Analysis}

The exon-intron structures of FtDofs and the presence or absence of the Dof domain were analysed on the basis of CDD results by using TBtools (version v1.0986853, https: //github.com/CJ-Chen/TBtools, accessed on 5 September 2020) [40] to investigate the differences in genes and proteins among the FtDofs family. The conserved motifs of the Dof proteins from Tartary buckwheat were searched using the MEME Suite (https:/ / memesuite.org/meme/tools / meme, accessed on 5 September 2020), where the maximum number of motifs was set to 10 and the remaining parameters were set to default values. The cisacting elements in the $2.0 \mathrm{~kb}$ promoter region upstream of the FtDofs were analysed using PlantCARE (http:/ / bioinformatics.psb.ugent.be/webtools/plantcare/html/, accessed on 9 September 2020).

\subsection{Chromosome Location, Gene Duplication and Synteny Analysis}

Detailed information on the identified FtDofs was obtained from the Tartary buckwheat genome project, and then the genes were numbered in accordance with their distribution on chromosomes. The multiple collinear scanning toolkit (MCScanX, http:/ / chibba.pgml. uga.edu/mcscan2/, accessed on 6 September 2020) was used to detect gene duplication events [41]. Syntenic analyses were conducted on FtDofs and the Dof family protein sequences of Glycine max, S. lycopersicum, Vitis vinifera, O. sativa, Setaria italica and S. bicolor obtained from PlantTFDB v5.0 (http:/ / planttfdb.gao-lab.org/, accessed on 10 September 2020) together with AtDofs obtained from the TAIR database by using TBtools.

\subsection{Plant Materials and Treatments}

The Tartary buckwheat accession 'Zhenba-3' used in this study was provided by the Minor Grain Research Centre, Northwest A \& F University, Yangling, Shaanxi, China. The variety was cultivated at the test site of the Baoji Academy of Agricultural Sciences, Shaanxi, China, on 25 June 2019. The region of the test site has a warm temperate semihumid climate. The management measures during the growth of Tartary buckwheat were implemented in accordance with the local production practice and crop demand. The roots, stems and leaves of Tartary buckwheat were collected at the squaring stage, and the fruits were collected at four different developmental stages, i.e., 3, 10, 17 and 24 days after pollination, corresponding to the initial formation stage (F_S1), green fruit stage (F_S2), discolouration stage (F_S3) and initial maturity stage (F_S4), respectively. All samples were collected from at least three plants and then immediately frozen in liquid nitrogen. 
Different exogenous hormone treatments were conducted to investigate the Tartary buckwheat Dof gene family's response to hormones. The Tartary buckwheat accession 'Zhenba-3' was planted in the experimental site of Northwest A \& F University. Furthermore, when seedlings grew to the three-leaf one-heart stage, they were treated with $100 \mu \mathrm{M}$ methyl jasmonate (MeJA), $100 \mu \mathrm{M}$ abscisic acid (ABA), $100 \mu \mathrm{M}$ salicylic acid (SA), $10 \mu \mathrm{M}$ indole-3-acetic acid (IAA) and $10 \mu \mathrm{M}$ gibberellin (GA) by foliar spray and treated with deionised water as a blank control. The second leaf of the seedling was harvested $6 \mathrm{~h}$ after treatments [42] and then quickly frozen in liquid nitrogen. Three biological replicates were performed for each sample.

\subsection{Expression Analyses of FtDof Genes by qRT-PCR}

Total RNA was extracted with Plant RNA Extraction Kit (TaKaRa, Takara Bio Inc., Tokyo, Japan) and treated with DNase I (TaKaRa, Takara Bio Inc., Tokyo, Japan) to remove genomic DNA. Then, approximately $2 \mu \mathrm{g}$ of the total RNA was used to synthesise cDNA with PrimeScript ${ }^{\mathrm{TM}}$ II 1st Strand cDNA Synthesis Kit (TaKaRa, Takara Bio Inc., Tokyo, Japan) in accordance with the manufacturer's instructions. The coding sequences (CDSs) of FtDofs were obtained from the Tartary buckwheat genome project. Primers for qRT-PCR (Table S1) were designed with Primer3 (version 4.1.0, https: / / primer3.ut.ee/, accessed on 10 June 2021), and the amplification efficiency was more than $90 \%$. qRT-PCR was performed on the Q7 Real-Time PCR System (Applied Biosystems ${ }^{\mathrm{TM}}$, Foster City, CA, USA) using the TB Green $^{\mathrm{TM}}$ Premix Ex Taq ${ }^{\mathrm{TM}}$ II (TaKaRa, Takara Bio Inc., Tokyo, Japan). The Tartary buckwheat histone H3-encoding gene was selected as the internal reference gene, and calculation was carried out in accordance with the $2^{-(\Delta \Delta C t)}$ method [43]. The expression data of each gene were first normalised by the Z-score method and then drawn as a heatmap. Each treatment included three biological replicates and three technical replicates. Finally, Student's $t$-test was conducted using $\mathrm{R}$ software to examine whether the expression of FtDofs changed significantly after exogenous hormone treatments compared with that after control treatment.

\subsection{Gene Ontology (GO) and Kyoto Encyclopedia of Genes and Genomes (KEGG) Enrichment Analysis of FtDof Proteins}

GO and KEGG enrichment analyses were conducted using online OmicShare tools (https:/ / www.omicshare.com/tools, accessed on 28 August 2021).

\section{Results}

\subsection{Genome-Wide Identification of FtDofs in Tartary Buckwheat}

Through retrieval and subsequent multi-verification, 35 Dof proteinswere identified in the Tartary buckwheat genome (Table S2). In accordance with the distribution order of Dof genes on the chromosome, FtDofs were assigned names from FtDof1 to FtDof35 (Figure 1). Then, the basic characteristics of FtDofs, including CDS length, protein length, Mw, $p \mathrm{I}$ and subcellular localisation, were investigated (Table 1). The CDS length of FtDofs ranged from $393 \mathrm{bp}$ (FtDof28) to $1416 \mathrm{bp}$ (FtDof25), the amino acid length of the corresponding proteins varied from 130 aa to 471 aa, and their Mw ranged from $14.8 \mathrm{kDa}$ to $50.8 \mathrm{kDa}$. The $p$ I of FtDof proteins ranged from 4.46 (FtDof8) to 9.84 (FtDof7). The results of subcellular localisation prediction indicated that all FtDof proteins are localised in the nucleus. 


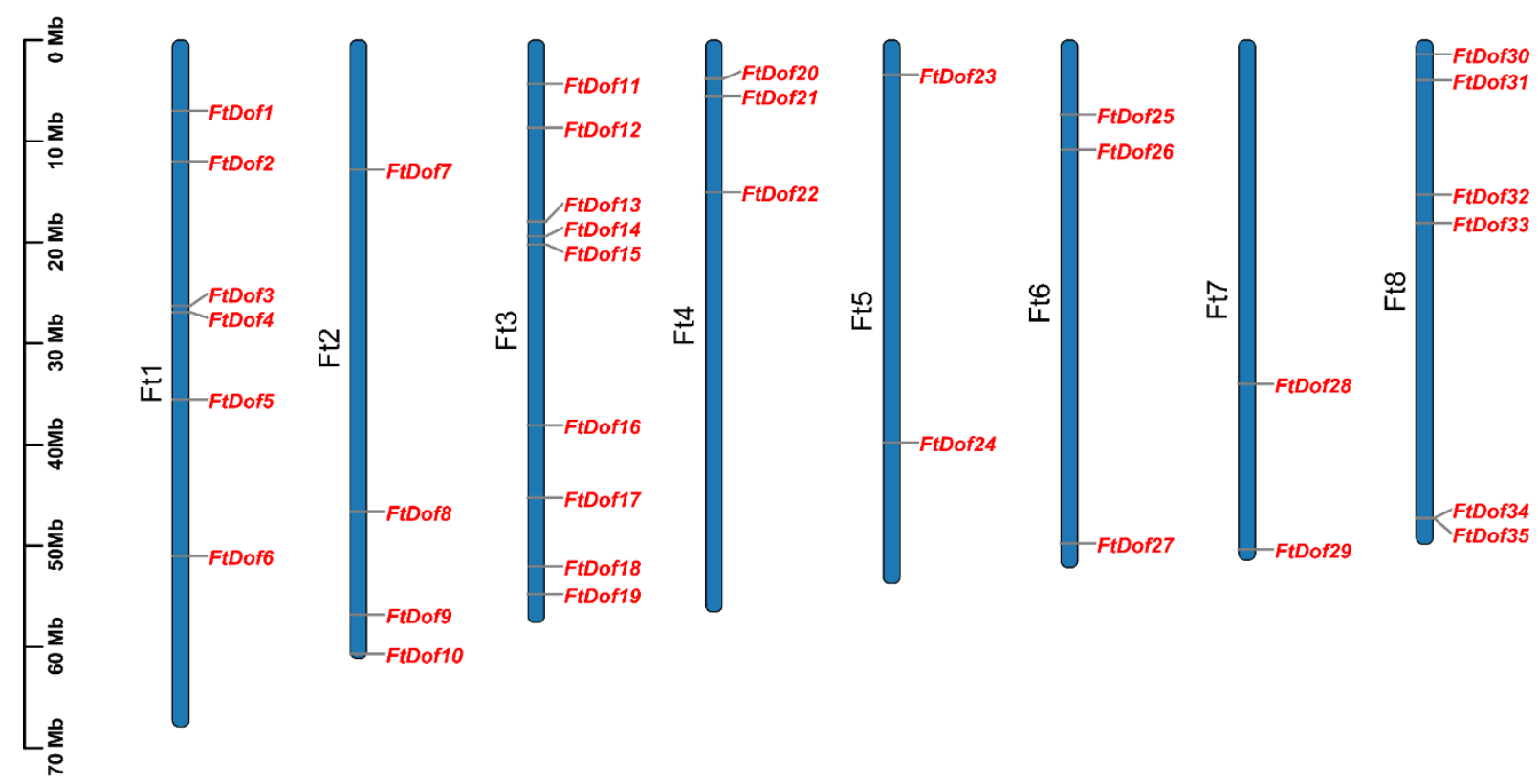

Figure 1. Schematic of chromosomal distribution of Tartary buckwheat Dof genes.

Table 1. Dof family genes in Tartary buckwheat.

\begin{tabular}{|c|c|c|c|c|c|c|c|}
\hline $\begin{array}{l}\text { Gene } \\
\text { Name }\end{array}$ & Gene ID & Chr Location & $\begin{array}{c}\text { CDS } \\
\text { Length (bp) }\end{array}$ & $\begin{array}{c}\text { Protein } \\
\text { Length (aa) }\end{array}$ & Mw (kDa) & $p \mathbf{I}$ & $\begin{array}{l}\text { Subcellular } \\
\text { Location }\end{array}$ \\
\hline FtDof1 & FtPinG0002490200.01.T01 & Ft1:6984896-6985480 & 555 & 184 & 20.91976 & 9.23 & Nuclear \\
\hline FtDof2 & FtPinG0005819100.01.T01 & Ft1:11995949-11997181 & 1023 & 340 & 37.16502 & 6.88 & Nuclear \\
\hline FtDof3 & FtPinG0006052400.01.T01 & Ft1:26283542-26284756 & 1029 & 342 & 37.13006 & 7.13 & Nuclear \\
\hline FtDof4 & FtPinG0000038100.01.T01 & Ft1:26894633-26895469 & 786 & 261 & 26.95576 & 6.29 & Nuclear \\
\hline FtDof5 & FtPinG0006014000.01.T01 & Ft1:35519701-35521178 & 1116 & 371 & 39.08230 & 9.15 & Nuclear \\
\hline FtDof6 & FtPinG0000383700.01.T01 & Ft1:51008719-51009996 & 828 & 275 & 30.39486 & 8.88 & Nuclear \\
\hline FtDof7 & FtPinG0007854200.01.T01 & Ft2:12819999-12820866 & 735 & 244 & 26.69874 & 9.84 & Nuclear \\
\hline FtDof8 & FtPinG0009668700.01.T01 & Ft2:46641998-46642846 & 846 & 281 & 31.58071 & 4.46 & Nuclear \\
\hline FtDofg & FtPinG0003838400.01.T01 & Ft2:56803328-56804871 & 729 & 242 & 26.43628 & 9.23 & Nuclear \\
\hline FtDof10 & FtPinG0000870700.01.T01 & Ft2:60683203-60684009 & 792 & 263 & 29.30853 & 7.13 & Nuclear \\
\hline FtDof11 & FtPinG0003987600.01.T01 & Ft3:4327917-4328955 & 879 & 292 & 32.09061 & 8.60 & Nuclear \\
\hline FtDof12 & FtPinG0006042300.01.T01 & Ft3:8679735-8681642 & 1089 & 362 & 39.37413 & 6.55 & Nuclear \\
\hline FtDof13 & FtPinG0001985100.01.T01 & Ft3:17940022-17941017 & 954 & 317 & 34.10505 & 8.84 & Nuclear \\
\hline FtDof14 & FtPinG0009592200.01.T01 & Ft3:19407541-19409658 & 846 & 281 & 31.00104 & 9.56 & Nuclear \\
\hline FtDof15 & FtPinG0006943800.01.T01 & Ft3:20185865-20187740 & 1209 & 402 & 44.58969 & 7.58 & Nuclear \\
\hline FtDof16 & FtPinG0001746600.01.T01 & Ft3:38071212-38072846 & 969 & 322 & 35.98977 & 8.57 & Nuclear \\
\hline FtDof17 & FtPinG0006517000.01.T01 & Ft3:45271193-45272090 & 756 & 251 & 27.20933 & 9.32 & Nuclear \\
\hline FtDof18 & FtPinG0001221400.01.T01 & Ft3:52038929-52039519 & 519 & 172 & 19.48991 & 9.08 & Nuclear \\
\hline FtDof19 & FtPinG0002126900.01.T01 & Ft3:54786097-54786807 & 696 & 231 & 26.33179 & 4.83 & Nuclear \\
\hline FtDof 20 & FtPinG0006352100.01.T01 & Ft4:3820883-3823102 & 1305 & 434 & 47.49093 & 6.05 & Nuclear \\
\hline FtDof 21 & FtPinG0000044800.01.T01 & Ft4:5503745-5504860 & 1029 & 342 & 37.27505 & 6.00 & Nuclear \\
\hline FtDof 22 & FtPinG0005157600.01.T01 & Ft4:15029533-15030375 & 750 & 249 & 27.95802 & 9.15 & Nuclear \\
\hline FtDof 23 & FtPinG0000644200.01.T01 & Ft5:3393885-3394904 & 831 & 276 & 31.16242 & 6.13 & Nuclear \\
\hline FtDof 24 & FtPinG0007868100.01.T01 & Ft5:39770127-39770799 & 639 & 212 & 23.72748 & 8.61 & Nuclear \\
\hline FtDof 25 & FtPinG0007057700.01.T01 & Ft6:7340538-7343583 & 1416 & 471 & 50.79071 & 6.20 & Nuclear \\
\hline FtDof 26 & FtPinG0006338000.01.T01 & Ft6:10848783-10849422 & 423 & 140 & 15.48469 & 9.21 & Nuclear \\
\hline FtDof 27 & FtPinG0000330300.01.T01 & Ft6:49780770-49782567 & 1008 & 335 & 36.87670 & 9.15 & Nuclear \\
\hline FtDof 28 & FtPinG0002571600.01.T01 & Ft7:33993961-33994407 & 393 & 130 & 14.84745 & 9.32 & Nuclear \\
\hline FtDof 29 & FtPinG0009543500.01.T01 & Ft7:50345602-50346563 & 858 & 285 & 31.47978 & 8.16 & Nuclear \\
\hline FtDof30 & FtPinG0002293400.01.T01 & Ft8:1391182-1394031 & 990 & 329 & 36.68763 & 7.62 & Nuclear \\
\hline FtDof31 & FtPinG0002167800.01.T01 & Ft8:3967827-3968546 & 720 & 239 & 26.66127 & 5.13 & Nuclear \\
\hline FtDof32 & FtPinG0008252900.01.T01 & Ft8:15269916-15270644 & 675 & 224 & 23.02970 & 8.57 & Nuclear \\
\hline FtDof33 & FtPinG0004209600.01.T01 & Ft8:18068180-18069652 & 1092 & 363 & 37.55589 & 9.03 & Nuclear \\
\hline FtDof34 & FtPinG0005937800.01.T01 & Ft8:47262582-47263547 & 702 & 233 & 26.2462 & 6.44 & Nuclear \\
\hline FtDof35 & FtPinG0000702500.01.T01 & Ft8:47316870-47317455 & 531 & 176 & 19.33684 & 9.39 & Nuclear \\
\hline
\end{tabular}




\subsection{Phylogenetic Analysis and Classification of FtDof Proteins}

A phylogenetic tree was constructed on the basis of 35 FtDofs identified in this study, together with 36 Dof proteins from $A$. thaliana, to explore the evolutionary relationships of Dof proteins in Tartary buckwheat (Figure 2). The result showed that 71 Dof proteins were classified into four major groups (A, B, C and D) and further divided into nine subgroups (A, B1, B2, C1, C2.1, C2.2, C3, D1 and D2). Each group or subgroup contained FtDofs, but their distributions were heterogeneous. Group $\mathrm{C}$ was the largest group, containing 15 genes and accounting for $42.86 \%$ of the total number of FtDofs, whereas group A was the smallest group and contained only 4 genes, accounting for $11.43 \%$ of the total number of FtDofs. Groups B and D contained seven and nine FtDofs, respectively.

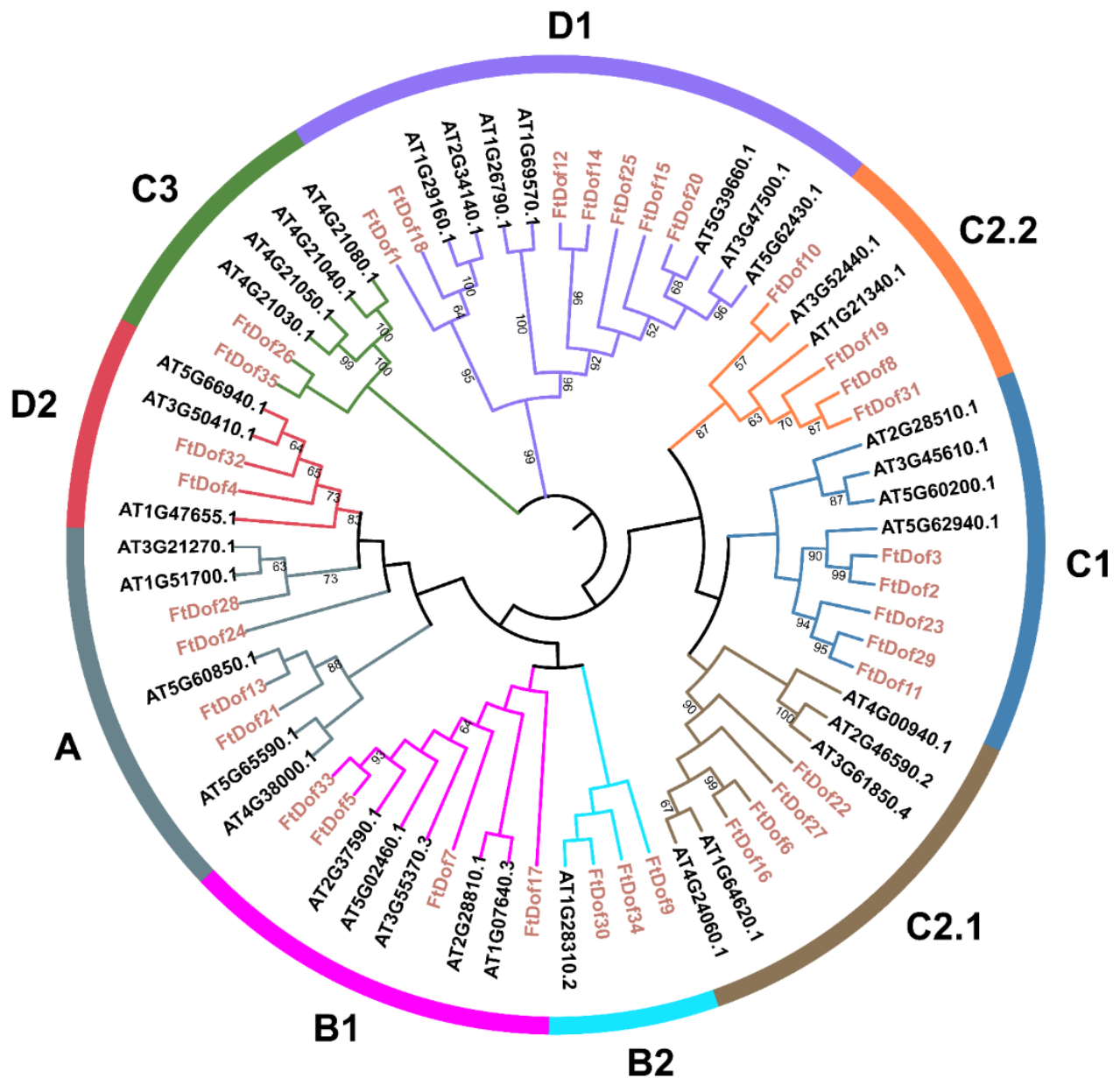

Figure 2. Phylogenetic tree constructed with Dof proteins from Tartary buckwheat and Arabidopsis thaliana by MEGA X (version 10.0.4) based on maximum likelihood method.

\subsection{Gene Structure and Conserved Motif Analysis of FtDof Genes}

The exon-intron structure of the 35 FtDofs was analysed on the basis of genomic DNA sequences (Figure 3a). Generally, the difference in the number of introns in each FtDof gene was very small, ranging from 0 to 2. Only three FtDof genes (FtDof33, FtDof30 and FtDof14) contained two introns, and they belonged to subgroups B1, B2 and D1, respectively. A total of 15 FtDof gene members had no introns (42.86\%), and 17 members had only one intron $(48.57 \%)$. Interestingly, the FtDof gene members belonging to the C1 subgroup contained only one intron, and the genes belonging to the A, C2.2, C3 and D2 subgroups lacked introns, indicating that the FtDof genes from the same subgroup have a similar gene structure. 
a

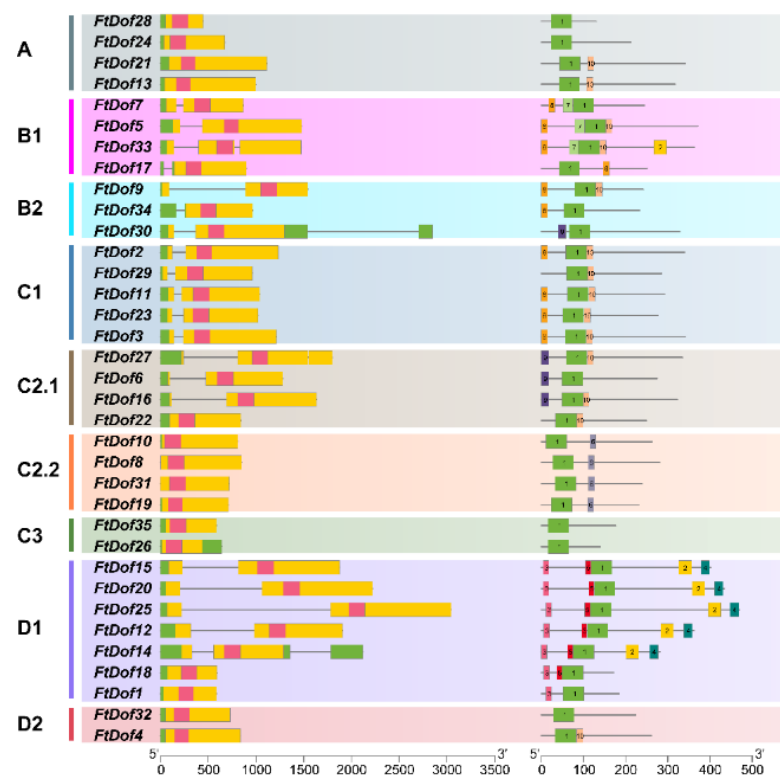

b

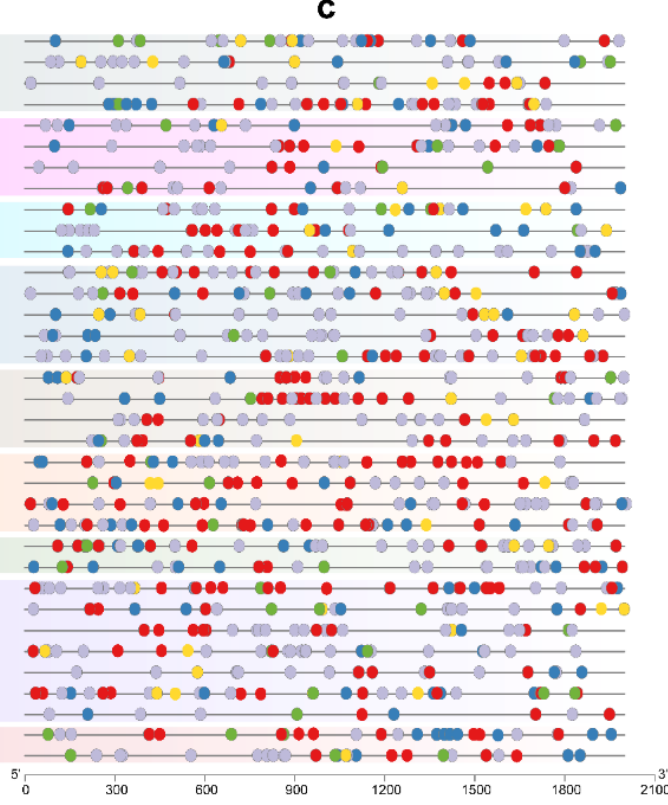

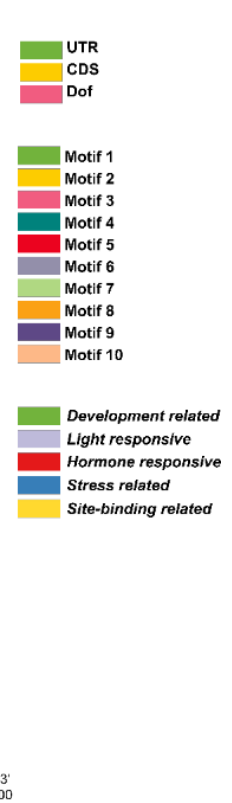

Figure 3. Gene structure, motif composition and cis-acting element distribution of Dof genes in Tartary buckwheat. (a) Exon-intron structures of Dof genes in Tartary buckwheat. The green box represents the untranslated region, the yellow box represents the coding sequence, and the red box represents the Dof domain. (b) Motif composition of Dof proteins in Tartary buckwheat. As shown in the legend on the right, Motifs 1-10 are marked with different colours. (c) Distribution of cis-acting elements in the promoter region of Tartary buckwheat Dof genes. Different types of cis-elements are marked with different colours, as indicated in the legend to the right.

The putative motifs were analysed by MEME to investigate the diversity of motif compositions among different $F t$ Dof proteins. As shown in Figure $3 b, 10$ distinct motifs were identified (Table S3). Motif 1 was present in all FtDofs, which corresponded to the conserved Dof domain. Moreover, motif 10 was widely present in 14 FtDof proteins. Therefore, it was considered to be another conserved domain. FtDof proteins belonging to the same subgroup had similar motif composition. Motif 2 was mainly present in the D1 subgroup and one member of the B1 subgroup (FtDof33). Motifs 3, 4 and 5 only appeared in the D1 subgroup, where all $F t$ Dof proteins in the D1 subgroup contained motif 3. Motifs 6 and 7 were exclusively present in subgroups C2.2 and B1, respectively. Motif 8 was widely present but limited to B1, B2 and C1 subgroups. Motif 9 was present in the C2.1 subgroup except for $F t$ Dof 22 and one member of the B2 subgroup (FtDof30). In general, similar to gene structure, FtDof proteins belonging to the same subgroup possessed similar motif composition.

\subsection{Promoter cis-Acting Element Analysis of FtDof Genes}

The cis-acting elements in the promoter regions were investigated to predict the potential functions of the FtDofs (Figure $3 \mathrm{c}$ and Table S4). Light-responsive elements were widely present in all FtDof genes. Furthermore, some development-related elements (e.g., AACA_motif, GCN4_motif and CAT-box), stress-related elements (e.g., LTR, MBS and WUN-motif) and site-binding-related elements (e.g., MBSI, CCAAT-box and AT-rich element) were still present in the FtDof genes, but not every FtDof gene contained them. Notably, almost all FtDof genes had a considerable number of hormone-responsive elements (e.g., GARE-motif, P-box and TATC-box), though the specific number differed, ranging from 3 to 24, indicating that the response of different FtDof genes to hormones may vary greatly. Interestingly, the cis-acting elements involved in ABA responsiveness (W-box and ABRE) and MeJA responsiveness (CGTCA-motif and TGACG-motif) were the most abundant among the hormone-responsive elements, reaching 191 and 100, respectively. The 
results suggest that FtDof genes may play an important role in hormone signal transduction, especially in response to $\mathrm{ABA}$ and MeJA.

\subsection{Gene Duplication and Synteny Analysis of FtDof Proteins}

As shown in Figure 1, 35 FtDof genes were unevenly distributed on the eight chromosomes of Tartary buckwheat, with six, four, nine, three, two, three, two and six genes, respectively. The MCScanX program was used to investigate whether gene duplication events took place in the Tartary buckwheat genome. The results showed no tandem duplication events amongst the FtDofs. However, 10 pairs of segmental duplication events were found, namely, FtDof1/FtDof18, FtDof2/FtDof3, FtDof5/FtDof33, FtDof6/FtDof16, FtDof8/FtDof31, FtDof9/FtDof33, FtDof11/FtDof23, FtDof11/FtDof29, FtDof13/FtDof21 and FtDof23/FtDof29 (Figure 4), indicating that segmental duplication was the primary driving force for the evolution of the FtDof gene family.

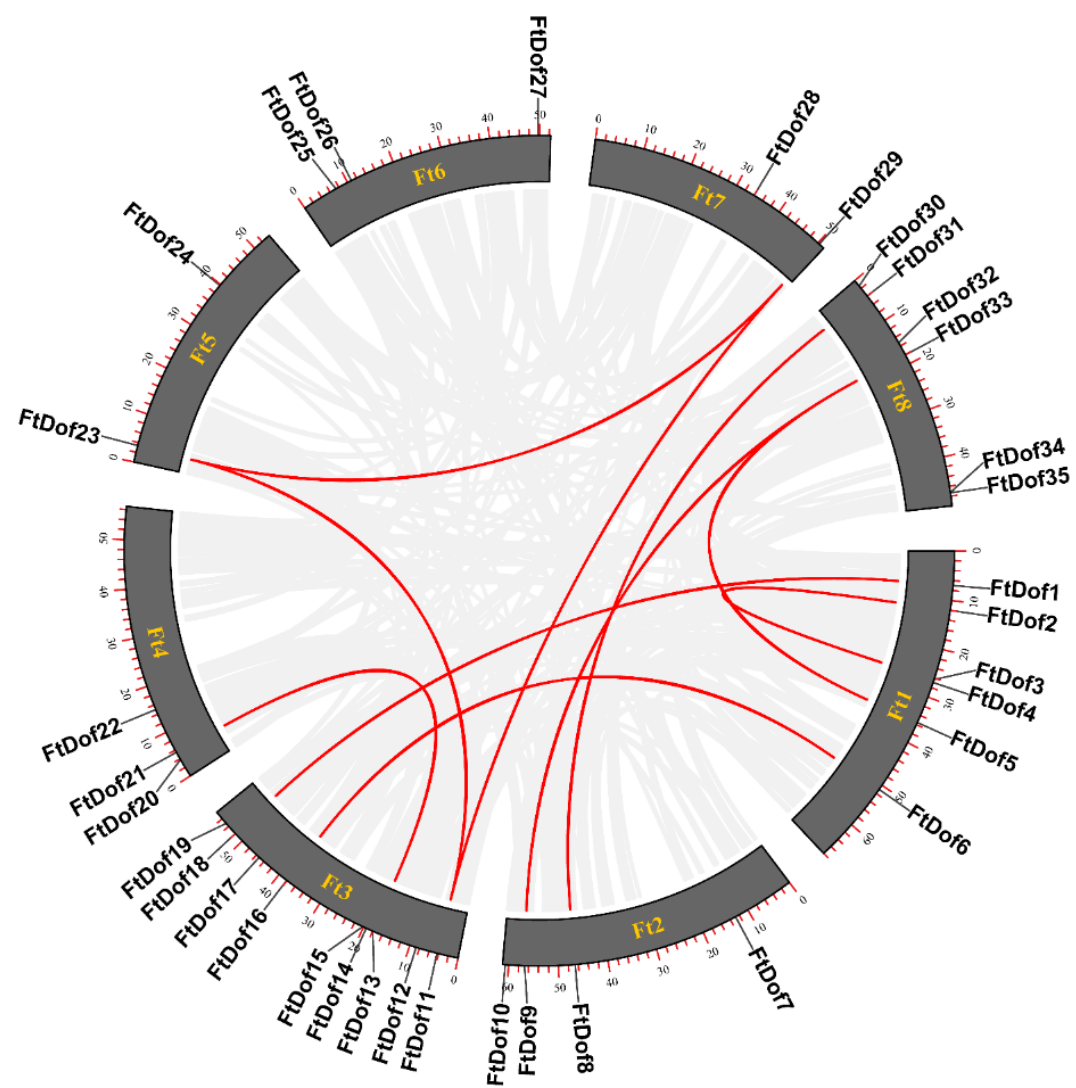

Figure 4. Schematic of interchromosomal relationship of Tartary buckwheat Dof proteins. Red lines represent segmental duplication events.

A synteny analysis on the Dof proteins from Tartary buckwheat and four dicotyledonous crops (A. thaliana, S. lycopersicum, G. max and V. vinifera) and three monocotyledonous crops (O. sativa, S. bicolor and S. italica) was conducted with MCScanX to explore the evolutionary relationship between Dof proteins from Tartary buckwheat and other representative crops (Figure 5). The numbers of gene pairs homologous to FtDofs were 20 (A. thaliana), 34 (G. max), 14 (V. vinifera), 24 (S. lycopersicum), 2 (O. sativa), 2 (S. bicolor) and 2 (S. italica) (Table S5). Generally, Tartary buckwheat had more orthologous genes with dicotyledons than with monocotyledons. In particular, FtDofs had the most collinear gene pairs within G. max, which were FtDof2, FtDof3, FtDof30 and FtDof34. Interestingly, FtDof33 had collinear gene pairs with plants other than G. max and two collinear gene pairs within all monocotyledons. 


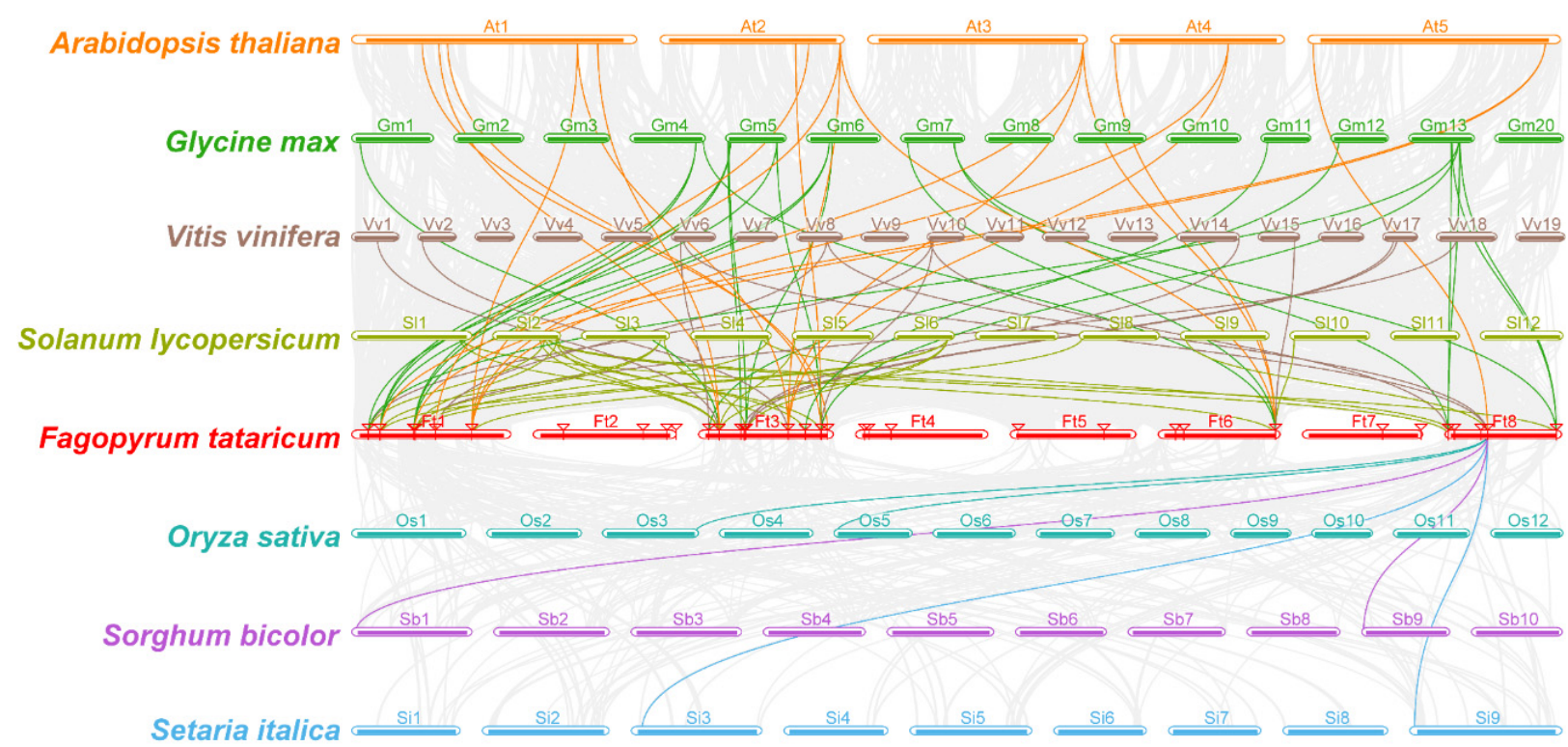

Figure 5. Synteny analysis between the Dof proteins of Tartary buckwheat with four dicotyledonous plants (Arabidopsis thaliana, Solanum lycopersicum, Glycine max and Vitis vinifera) and three monocotyledonous plants (Oryza sativa, Setaria italica and Sorghum bicolor) by MCScanX.

3.6. Expression Pattern of FtDof Genes in Different Tissues and in Different Fruit Developmental Stages of Tartary Buckwheat

The expression levels of 35 FtDof genes in Tartary buckwheat roots, stems, leaves and four developmental stages of fruit (F_S1, F_S2, F_S3 and F_S4) were characterised by qRT-PCR assay to gain insight into the potential roles of these genes (Figure 6a). Generally, the expression pattern of each gene varied greatly in different tissues, and they could be divided into four groups. Eleven genes in group I had relatively high expression levels in Tartary buckwheat fruit, but their dynamic expression patterns differed among the four developmental stages. The expression of FtDof26 first increased and then decreased with fruit development, reaching the highest expression in the S2 stage. FtDof13/24/6/29/31 were highly expressed in S1 and S3 stages, especially in the S3 stage. Additionally, the expression of FtDof4/32/35/22/25 first decreased and then increased with fruit development. Seven genes in group II were all lowly expressed in fruits. Amongst them, FtDof33/16/30 were highly expressed in roots, stems and leaves. The expression levels of FtDof12 and FtDof15 were higher in stems and leaves. FtDof9 and FtDof14 were specifically highly expressed in leaves. A notable detail was that all genes in group III were specifically expressed in roots and lowly expressed in other tissues. Eight genes in group IV had relatively high expression levels in stems, and they were expressed in other tissues to varying degrees.

\subsection{Expression Pattern of FtDof Genes under Different Hormone Treatments}

Analysis of the cis-acting elements in the promoter region of FtDof genes demonstrated that most genes contained abundant hormone-responsive elements. Thus, Tartary buckwheat seedlings were treated with five hormones (ABA, GA, IAA, MeJA and SA) to observe the response of FtDof genes. The statistical results showed that the expression of more than $40 \%$ genes changed significantly, specifically, 57.14\% (5 upregulated and 15 downregulated) under ABA treatment, 42.86\% (2 upregulated and 13 downregulated) under GA treatment, 54.29\% (6 upregulated and 13 downregulated) under IAA treatment, 42.86\% (12 upregulated and 3 downregulated) under MeJA treatment and 42.86\% (2 upregulated and 13 downregulated) under SA treatment (Figure 6b). 


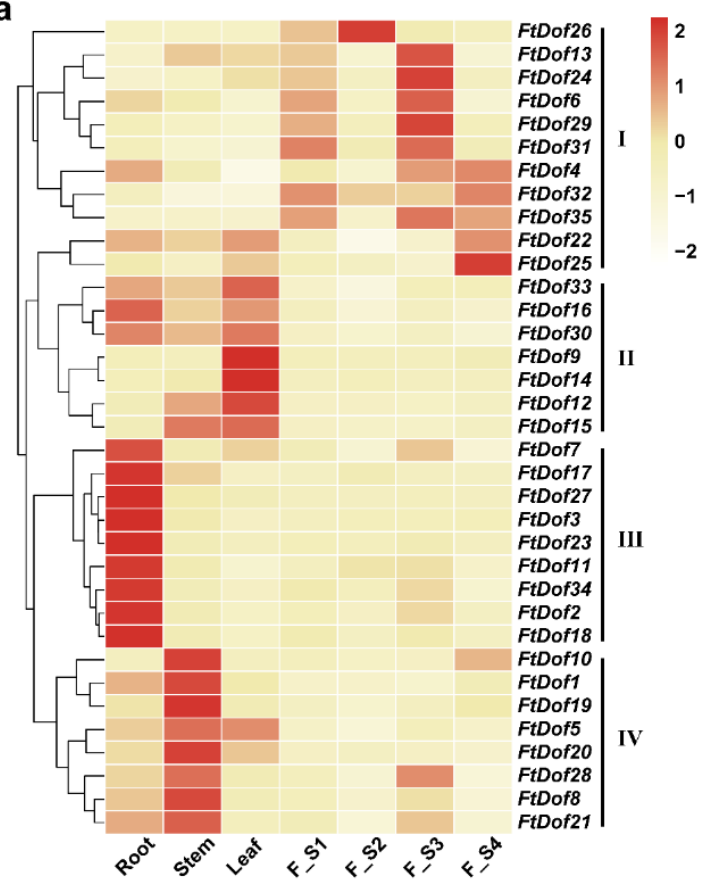

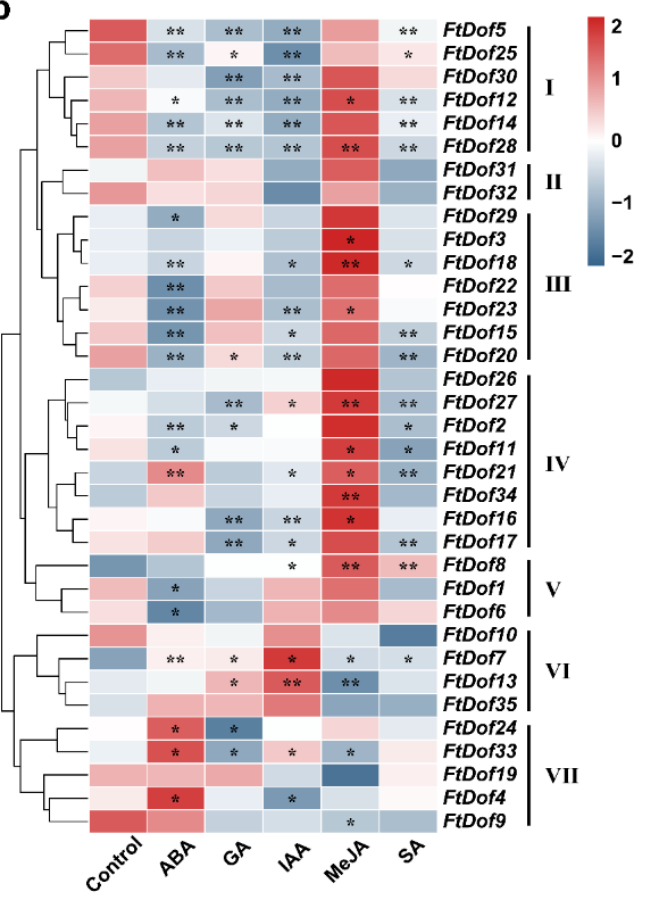

Figure 6. Heatmap of tissue specificity of Tartary buckwheat Dof genes and expression pattern after stimulation with exogenous hormones. (a) Expression pattern of FtDofs in Tartary buckwheat roots, stems, leaves and four developmental stages of fruit (F_S1, F_S2, F_S3 and F_S4). With the increase in gene expression, the colour of the bar shifts from white to red, as shown in the bar on the right. (b) Expression pattern of FtDofs after stimulation with exogenous hormones. The asterisk on the heatmap indicates a significant difference between the treatment and the control (Student's $t$-test). * and ${ }^{* *}$ represent 0.05 and 0.01 significance levels, respectively. With the increase in gene expression, the colour of the bar shifts from blue to red, as shown in the bar on the right.

FtDof genes were divided into seven groups (groups I-VII) in accordance with the overall expression patterns under hormone treatment. Group I contained six genes. Almost all of their expression levels changed under the five hormone treatments. The expression levels were downregulated under treatments with ABA, GA, IAA and SA. Except for FtDof5 and FtDof25, the expression levels of other genes were all upregulated under MeJA treatment, especially those of FtDof $12(p<0.05)$ and FtDof $28(p<0.01)$. The expression levels of FtDof31 and FtDof32 in group II did not appear to be sensitive to any of the five hormone treatments. Group III was downregulated by ABA, IAA and SA treatments and upregulated by MeJA treatment. In group IV, the gene expression was upregulated under MeJA treatment and downregulated by SA treatment. Amongst the three genes in group $\mathrm{V}$, the expression of FtDof 8 was significantly upregulated under IAA, MeJA and SA treatments, whilst the expression levels of FtDof1 and FtDof6 were significantly downregulated under ABA treatment. Groups VI and VII showed different patterns from those of groups I-V. The MeJA treatment was associated with the upregulation of FtDof genes in groups I-V and the downregulation of gene groups VI and VII. Conversely, the ABA and IAA treatments were associated with the overall downregulation of FtDof genes in groups I-V and an upregulation of genes in groups VI and VII. Overall, the 35 FtDof genes were generally downregulated by SA treatment.

\subsection{GO and KEGG Enrichment Analysis of FtDof Proteins}

GO and KEGG enrichment analyses were carried out on the basis of the annotation database to investigate the functional category distribution of $F t$ Dof proteins (Table S6). The result of GO enrichment showed (Figure 7a) that FtDof proteins were distributed in three GO ontologies, namely, molecular function, cellular component and biological 
process. For molecular function, all but one transcription regulator activity belonged to the 'binding' category. The molecular functions were all related to the intracellular organelle. For biological processes, almost all items referred to 'metabolic', 'biosynthetic' or tissue development. The KEGG enrichment results showed that only one protein, FtDof14 (FtPinG0009592200.01.T01), was enriched and distributed in three pathways, namely, circadian rhythm-plant, environmental adaptation and organismal systems (Figure $7 \mathrm{~b}$ and Table S6).

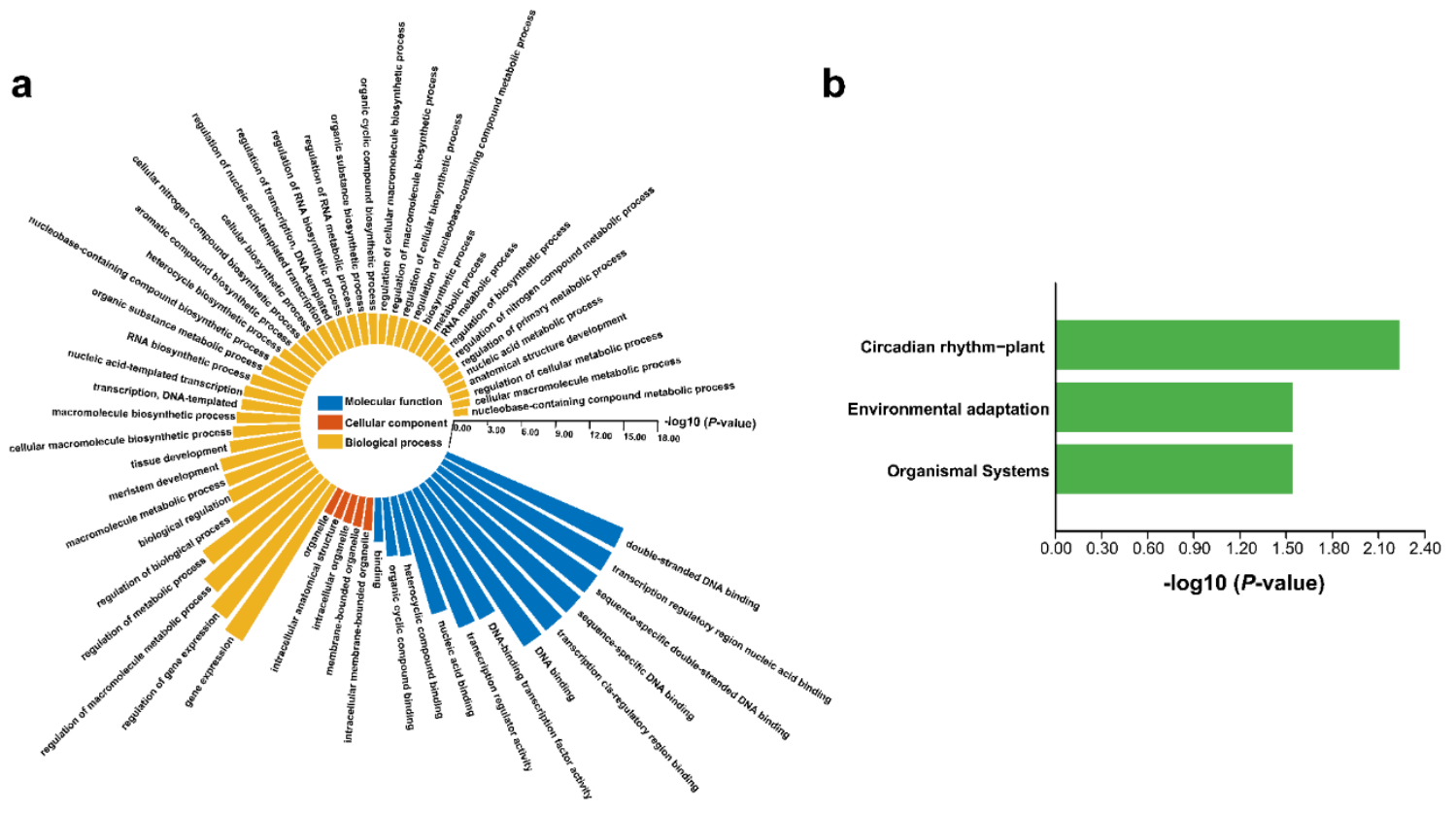

Figure 7. Enrichment analysis of FtDofs. (a) Gene ontology (GO) enrichment analysis of FtDofs. Blue, red and yellow represent three ontologies of GO, namely, molecular function, cellular component and biological process, respectively. (b) Kyoto Encyclopedia of Genes and Genomes (KEGG) enrichment analysis of FtDofs.

\section{Discussion}

\subsection{Molecular Characterisation and Evolution of FtDof Proteinsin Tartary Buckwheat}

Due to the special role of TFs in regulating gene expression, identifying and functionally characterising gene families that are widely present in the genome are important to further understand the growth and development of plants and their responses to environmental stimuli [44]. In the present study, 35 FtDofs were identified in the Tartary buckwheat genome. The number of $F t$ Dofs was similar to that identified for $A$. thaliana (36 AtDofs) [8], rice (30 OsDofs) [8] and tomato (34 SlDofs) [12]. However, the genome sizes of these plants are quite different (Tartary buckwheat, $489.3 \mathrm{Mb}$ [36]; A. thaliana, $125 \mathrm{Mb}$ [45]; rice, $466 \mathrm{Mb}$ [46]; and tomato, $900 \mathrm{Mb}$ [47]), implying that the number of Dof proteinsis independent of genome size.

Phylogenetic analysis indicated that FtDofs could be classified into nine subgroups by using the optimal model of the ML method (Figure 2), consistent with the analysis of the Dof gene family in watermelon [48]. The exon-intron structure analysis revealed that the gene structures amongst different subgroups were substantially different, but generally, similar structures were observed within the subgroups (Figure 3a). Additionally, the number of introns in FtDofs was relatively small, ranging from 0 to 2, and most genes had no introns or only one intron. As mentioned in previous studies, the low number of introns may be related to the stress response [49]. As with the results of the exon-intron structure analysis, the arrangement of the FtDof motifs within the subgroup was generally consistent, but notable differences were found amongst the subgroups (Figure $3 b$ ). The findings indicate the possibility of great differences in the function of $F t$ Dofs amongst different subgroups. Nevertheless, all identified proteinshad a common motif (motif 1), 
the conserved Dof domain, which may be involved in binding to a particular promoter sequence [13]. Motif 10 is thought to be another conserved domain, which is likely to be a molecular hinge connecting the two domains as a serine stretch [4]. Moreover, almost every subgroup had its own unique and nearly conservative motifs. For example, motifs $3 / 4 / 5$ only existed in the D1 subgroup, and motif 6 only existed in the C2.2 subgroup. Interestingly, in the $\mathrm{C} 1$ subgroup, except for $F t$ Dof 29 , all other proteinshad three motifs, motifs $1 / 8 / 10$, which may lead to functional differences. Therefore, the existence of these motifs endows FtDofs with different functions, resulting in the functional differentiation of FtDofs [48].

Gene duplication is a common phenomenon in the evolution of angiosperms, usually including tandem and segmental duplication, which could lead to the expansion of the gene family [50]. Studies have revealed that tandem and segmental duplication events exist simultaneously in PtrDofs [51]. However, in TaDofs, tandem duplication events only existed at the ends of chromosomes [13]. In the present study, no tandem duplication event was observed in FtDofs, but 10 pairs of segmental duplication events were detected (Figure 4), similar to the results obtained for watermelon [48] and cotton [52]. This finding indicated that the expansion of $F t$ Dofs was mainly due to segmental duplication. Collinearity analysis can provide insights into the evolutionary history of species [41]. In the present study, the number of collinear gene pairs between the Dof proteinsof Tartary buckwheat and dicotyledons was much higher than that of monocotyledons, especially within soybean (Figure 5), consistent with previous research results on ZF-HD [53], SPL [54] and NAC [55] gene families of Tartary buckwheat.

\subsection{Tissue-Specific Expression Characterisation of FtDof Genes in Tartary Buckwheat}

Previous studies revealed that Dof genes usually had tissue-specific expression patterns $[13,24,56]$, and similar phenomena were found in FtDof genes (Figure 6a). In the C1 subgroup, AT5G62940 (Dof5.6/HCA2) was involved in the regulation of interfascicular cambium formation and vascular tissue development [57], and it was highly expressed in the root meristem and elongation zones [58]. Similarly, AT5G60200 (TMO6) was expressed in the root meristem and elongation zones. The other two genes, AT3G45610 and AT2G28510, were proven to be expressed in all three developmental regions (meristem, elongation and differentiation zones) of roots. AT3G45610 and AT5G60200 were both pericycle-specific [58]. Similar expression patterns were also found in the $\mathrm{C} 1$ subgroup; that is, all members in this subgroup were highly expressed in roots except for FtDof 29 , which was low in roots but highly expressed in the F_S3 stage of fruit development. Interestingly, compared with the other four genes, FtDof 29 lacked motif 8 and only contained motif 1 and motif 10 . Therefore, the difference in the expression preference between FtDof 29 and other genes in the same subgroup was the absence of motif 8. FtDof2 and FtDof3 shared the same expression pattern, which was attributed to segmental duplication, indicating possible functional redundancy [48,59-61].

Five A. thaliana Dof genes in the B1 subgroup were highly expressed in root, stem and leaf tissues, and they played important biological functions. AT2G37590 played important roles in the early developmental stages of vascular tissues and in the development of procambial cells in leaf primordia, roots and embryos [15]. AT5G02460 was involved in the development of $A$. thaliana leaves, and it affected leaf axial patterns by promoting the transcription of Revoluta [62]. AT1G07640 (OBP2) was expressed in the vascular system of all $A$. thaliana organs, with high expression in roots and leaves and relatively weak expression in stems [63]. Moreover, AT3G55370 (OBP3) [64] and AT2G28810 [58] were highly expressed in $A$. thaliana roots. Similar expression patterns were found in the other four FtDof genes of Tartary buckwheat in the B1 subgroup. FtDof7 and FtDof17 were highly expressed in roots. FtDof5 and FtDof33 were also expressed in roots, stems and leaves. Their expression levels in fruits were the lowest.

The C3 subgroup contained six genes, of which four A. thaliana Dof genes (AT4G21030, AT4G21040, AT4G21050 and AT4G21080) were proven to be related to the development 
of seeds or mainly expressed in siliques [8,65]. Interestingly, the other two FtDof genes, FtDof 26 and FtDof35, were only highly expressed in fruit, showing exactly the same pattern as A. thaliana. Thus, FtDof 26 and FtDof35 may play key roles in the fruit development of Tartary buckwheat, but this needs further experimental verification.

\subsection{Expression Pattern of FtDof Genes in Response to Hormones}

The cis-acting elements present in the promoter region play pivotal roles in gene expression [66]. In the present study, several hormone-responsive elements were found in almost all promoter regions of FtDof genes, including ABA-, GA-, IAA-, MeJA- and SA-responsive elements (Table S4). The qRT-PCR analysis showed that the expression patterns of FtDof genes were inconsistent under different treatments. Specifically, FtDof genes were mainly upregulated under MeJA treatment but downregulated under other hormone treatments. Numerous previous studies have shown that various hormones usually regulate the expression of Dof genes. The transcription level of OBP2 in Arabidopsis [63] and $V v D O F 3$ in grape [67] increased significantly upon treatment with MeJA. However, the expression of BrDof2.4 in Chinese flowering cabbage was suppressed under MeJA treatment [68]. Similarly, the expression patterns of Dof genes in response to exogenous ABA [24], GA [69], IAA [13] and SA [70] treatments were complex and changeable in other plants. Additionally, studies have illustrated no direct correlation between the number of cis-acting elements and gene expression patterns [71,72]. In the present study, the expression levels of three genes, namely, FtDof7, FtDof 12 and FtDof28, changed significantly under treatment with five exogenous hormones. However, few hormone-responsive elements were present in their promoter regions. In particular, FtDof7 had only three cis-elements, TCA (SA-responsive), W box (ABA-responsive) and ABRE (ABA-responsive), implying the presence of complex regulatory mechanisms affecting the expression of FtDof genes.

\section{Conclusions}

In this study, $35 \mathrm{FtDof}$ proteins were identified on the basis of the Tartary buckwheat genome database, and these genes were classified into nine subgroups. The FtDof genes within each subgroup shared similar gene structure and motif arrangement, and they were distinguishable amongst subgroups. Some motifs were uniquely or even conservatively found in individual subgroups, presumably with specialised functions. Segmental duplication was the primary driving force for the evolution of the FtDof gene family. Moreover, the FtDof genes had clear expression specificity and preference in different tissues and fruit development stages, most of which were significantly regulated by the treatment with exogenous hormones. This finding indicates that FtDof genes may be involved in multiple biological processes during the growth and development of Tartary buckwheat. In conclusion, this study provides a foundation for further exploration of the functional characteristics of the Tartary buckwheat Dof gene family and its role in growth and development and resisting stress. It will also be helpful in improving varieties of Tartary buckwheat in the future.

Supplementary Materials: The following supporting information can be downloaded at: https: / / www.mdpi.com/article/10.3390/biology11020173/s1, Table S1: The primers of FtDofs used for qRT-PCR; Table S2: The CDS and protein sequences of FtDofs identified in this study; Table S3: The putative motifs identified in FtDof proteins by MEME; Table S4: The cis-acting elements in the promoter regions of FtDofs; Table S5: Orthologous gene pairs between Tartary buckwheat and seven other species; Table S6: Gene Ontology (GO) and Kyoto Encyclopedia of Genes and Genomes (KEGG) enrichment analysis of FtDof proteins.

Author Contributions: Conceptualisation, J.L.; methodology, J.L. and C.W.; software, J.L.; validation, J.L.; formal analysis, J.L. and C.W.; investigation, J.L., Y.Z., L.X., C.W. and Y.L.; data curation, J.L. and S.F.; writing — original draft preparation, J.L.; writing-review and editing, S.F., Y.Y. and Q.Y.; visualisation, J.L. and S.F.; supervision, B.F. All authors have read and agreed to the published version of the manuscript. 
Funding: This research was funded by the National Key R\&D Program of China, grant numbers 2019YFD1000700 and 2019YFD1000702; the National Natural Science Foundation of China, grant numbers 31671631 and 31501365; Shaanxi Province Modern Crops Seed Industry Project, grant number 20171010000004; and the Technical System Project of Minor Grain Crops Industry in Shaanxi Province, grant number NYKJ-2018-YL19.

Institutional Review Board Statement: Not applicable.

Informed Consent Statement: Not applicable.

Data Availability Statement: The data presented in this study are available in the article and its supplementary materials.

Acknowledgments: We thank all colleagues in our laboratory. They provided useful suggestions and technical assistance during the experimental preparation and composition of the manuscript. We are especially grateful to the editor and reviewers for their critical evaluation of the manuscript and constructive comments for its further completion and improvement.

Conflicts of Interest: The authors declare no conflict of interest.

\section{References}

1. Todeschini, A.L.; Georges, A.; Veitia, R.A. Transcription factors: Specific DNA binding and specific gene regulation. Trends Genet. 2014, 30, 211-219. [CrossRef] [PubMed]

2. Gupta, S.; Malviya, N.; Kushwaha, H.; Nasim, J.; Bisht, N.C.; Singh, V.K.; Yadav, D. Insights into structural and functional diversity of Dof (DNA binding with one finger) transcription factor. Planta 2015, 241, 549-562. [CrossRef] [PubMed]

3. Yanagisawa, S.; Sheen, J. Involvement of maize Dof zinc finger proteins in tissue-specific and light-regulated gene expression. Plant Cell 1998, 10, 75-89. [CrossRef] [PubMed]

4. Yanagisawa, S. The Dof family of plant transcription factors. Trends Plant Sci. 2002, 7, 555-560. [CrossRef]

5. Umemura, Y.; Ishiduka, T.; Yamamoto, R.; Esaka, M. The Dof domain, a zinc finger DNA-binding domain conserved only in higher plants, truly functions as a Cys2/Cys2 Zn finger domain. Plant J. 2004, 37, 741-749. [CrossRef]

6. Yanagisawa, S.; Schmidt, R.J. Diversity and similarity among recognition sequences of Dof transcription factors. Plant J. 1999, 17, 209-214. [CrossRef]

7. Yanagisawa, S.; Izui, K. Molecular cloning of two DNA-binding proteins of maize that are structurally different but interact with the same sequence motif. J. Biol. Chem. 1993, 268, 16028-16036. [CrossRef]

8. Lijavetzky, D.; Carbonero, P.; Vicente-Carbajosa, J. Genome-wide comparative phylogenetic analysis of the rice and Arabidopsis Dof gene families. BMC Evol. Biol. 2003, 3, 17. [CrossRef]

9. Moreno-Risueno, M.A.; Martinez, M.; Vicente-Carbajosa, J.; Carbonero, P. The family of DOF transcription factors: From green unicellular algae to vascular plants. Mol. Genet. Genom. 2007, 277, 379-390. [CrossRef]

10. Chen, Y.; Cao, J. Comparative analysis of Dof transcription factor family in maize. Plant Mol. Biol. Report. 2015, 33, 1245-1258. [CrossRef]

11. Kushwaha, H.; Gupta, S.; Singh, V.K.; Rastogi, S.; Yadav, D. Genome wide identification of Dof transcription factor gene family in sorghum and its comparative phylogenetic analysis with rice and Arabidopsis. Mol. Biol. Rep. 2011, 38, 5037-5053. [CrossRef]

12. Cai, X.; Zhang, Y.; Zhang, C.; Zhang, T.; Hu, T.; Ye, J.; Zhang, J.; Wang, T.; Li, H.; Ye, Z. Genome-wide analysis of plant-specific Dof transcription factor family in tomato. J. Integr. Plant Biol. 2013, 55, 552-566. [CrossRef]

13. Liu, Y.; Liu, N.; Deng, X.; Liu, D.; Li, M.; Cui, D.; Hu, Y.; Yan, Y. Genome-wide analysis of wheat DNA-binding with one finger (Dof) transcription factor genes: Evolutionary characteristics and diverse abiotic stress responses. BMC Genom. 2020, 21, 276. [CrossRef]

14. Noguero, M.; Atif, R.M.; Ochatt, S.; Thompson, R.D. The role of the DNA-binding One Zinc Finger (DOF) transcription factor family in plants. Plant Sci. 2013, 209, 32-45. [CrossRef] [PubMed]

15. Konishi, M.; Yanagisawa, S. Sequential activation of two Dof transcription factor gene promoters during vascular development in Arabidopsis thaliana. Plant Physiol. Biochem. 2007, 45, 623-629. [CrossRef]

16. Negi, J.; Moriwaki, K.; Konishi, M.; Yokoyama, R.; Nakano, T.; Kusumi, K.; Hashimoto-Sugimoto, M.; Schroeder, J.I.; Nishitani, K.; Yanagisawa, S.; et al. A Dof transcription factor, SCAP1, is essential for the development of functional stomata in Arabidopsis. Curr. Biol. 2013, 23, 479-484. [CrossRef]

17. Yang, J.; Yang, M.F.; Zhang, W.P.; Chen, F.; Shen, S.H. A putative flowering-time-related Dof transcription factor gene, JcDof3, is controlled by the circadian clock in Jatropha curcas. Plant Sci. 2011, 181, 667-674. [CrossRef]

18. Wu, Q.; Liu, X.; Yin, D.; Yuan, H.; Xie, Q.; Zhao, X.; Li, X.; Zhu, L.; Li, S.; Li, D. Constitutive expression of OsDof4, encoding a $\mathrm{C}_{2}-\mathrm{C}_{2}$ zinc finger transcription factor, confesses its distinct flowering effects under long- and short-day photoperiods in rice (Oryza sativa L.). BMC Plant Biol. 2017, 17, 166. [CrossRef] 
19. Chen, X.; Wang, D.; Liu, C.; Wang, M.; Wang, T.; Zhao, Q.; Yu, J. Maize transcription factor Zmdof1 involves in the regulation of Zm401 gene. Plant Growth Regul. 2012, 66, 271-284. [CrossRef]

20. Gualberti, G.; Papi, M.; Bellucci, L.; Ricci, I.; Bouchez, D.; Camilleri, C.; Costantino, P.; Vittorioso, P. Mutations in the Dof zinc finger genes DAG2 and DAG1 influence with opposite effects the germination of Arabidopsis seeds. Plant Cell 2002, 14, 1253-1263. [CrossRef] [PubMed]

21. Rueda-Romero, P.; Barrero-Sicilia, C.; Gomez-Cadenas, A.; Carbonero, P.; Onate-Sanchez, L. Arabidopsis thaliana DOF6 negatively affects germination in non-after-ripened seeds and interacts with TCP14. J. Exp. Bot. 2012, 63, 1937-1949. [CrossRef]

22. Marzabal, P.; Gas, E.; Fontanet, P.; Vicente-Carbajosa, J.; Torrent, M.; Ludevid, M.D. The maize Dof protein PBF activates transcription of gamma-zein during maize seed development. Plant Mol. Biol. 2008, 67, 441-454. [CrossRef]

23. Santos, L.A.; de Souza, S.R.; Fernandes, M.S. OsDof 25 expression alters carbon and nitrogen metabolism in Arabidopsis under high N-supply. Plant Biotechnol. Rep. 2012, 6, 327-337. [CrossRef]

24. Venkatesh, J.; Park, S.W. Genome-wide analysis and expression profiling of DNA-binding with one zinc finger (Dof) transcription factor family in potato. Plant Physiol. Biochem. 2015, 94, 73-85. [CrossRef] [PubMed]

25. Boccaccini, A.; Lorrai, R.; Ruta, V.; Frey, A.; Mercey-Boutet, S.; Marion-Poll, A.; Tarkowska, D.; Strnad, M.; Costantino, P.; Vittorioso, P. The DAG1 transcription factor negatively regulates the seed-to-seedling transition in Arabidopsis acting on ABA and GA levels. BMC Plant Biol. 2016, 16, 198. [CrossRef]

26. Lorrai, R.; Gandolfi, F.; Boccaccini, A.; Ruta, V.; Possenti, M.; Tramontano, A.; Costantino, P.; Lepore, R.; Vittorioso, P. Genomewide RNA-seq analysis indicates that the DAG1 transcription factor promotes hypocotyl elongation acting on ABA, ethylene and auxin signaling. Sci. Rep. 2018, 8, 15895. [CrossRef] [PubMed]

27. Kang, H.G.; Foley, R.C.; Onate-Sanchez, L.; Lin, C.; Singh, K.B. Target genes for OBP3, a Dof transcription factor, include novel basic helix-loop-helix domain proteins inducible by salicylic acid. Plant J. 2003, 35, 362-372. [CrossRef]

28. Su, Y.; Liang, W.; Liu, Z.; Wang, Y.; Zhao, Y.; Ijaz, B.; Hua, J. Overexpression of GhDof1 improved salt and cold tolerance and seed oil content in Gossypium hirsutum. J. Plant Physiol. 2017, 218, 222-234. [CrossRef] [PubMed]

29. Zhou, J.; Liu, D.; Deng, X.; Zhen, S.; Wang, Z.; Yan, Y. Effects of water deficit on breadmaking quality and storage protein compositions in bread wheat (Triticum aestivum L.). J. Sci. Food Agric. 2018, 98, 4357-4368. [CrossRef]

30. Sasaki, N.; Matsumaru, M.; Odaira, S.; Nakata, A.; Nakata, K.; Nakayama, I.; Yamaguchi, K.; Nyunoya, H. Transient expression of tobacco BBF1-related Dof proteins, BBF2 and BBF3, upregulates genes involved in virus resistance and pathogen defense. Physiol. Mol. Plant Pathol. 2015, 89, 70-77. [CrossRef]

31. Feng, S.; Li, J.; Qian, G.; Feng, B. Association between the yield and the main agronomic traits of Tartary buckwheat evaluated using the random forest model. Crop. Sci. 2020, 60, 2394-2407. [CrossRef]

32. Li, J.; Feng, S.; Qu, Y.; Gong, X.; Luo, Y.; Yang, Q.; Zhang, Y.; Dang, K.; Gao, X.; Feng, B. Identifying the primary meteorological factors affecting the growth and development of Tartary buckwheat and a comprehensive landrace evaluation using a multienvironment phenotypic investigation. J. Sci. Food Agric. 2021, 101, 6104-6116. [CrossRef] [PubMed]

33. Li, J.; Hossain, M.S.; Ma, H.; Yang, Q.; Gong, X.; Yang, P.; Feng, B. Comparative metabolomics reveals differences in flavonoid metabolites among different coloured buckwheat flowers. J. Food Compos. Anal. 2020, 85, 103335. [CrossRef]

34. Li, J.; Yang, P.; Yang, Q.; Gong, X.; Ma, H.; Dang, K.; Chen, G.; Gao, X.; Feng, B. Analysis of Flavonoid Metabolites in Buckwheat Leaves Using UPLC-ESI-MS/MS. Molecules 2019, 24, 1310. [CrossRef] [PubMed]

35. Zou, L.; Wu, D.; Ren, G.; Hu, Y.; Peng, L.; Zhao, J.; Garcia-Perez, P.; Carpena, M.; Prieto, M.A.; Cao, H.; et al. Bioactive compounds, health benefits, and industrial applications of Tartary buckwheat (Fagopyrum tataricum). Crit. Rev. Food Sci. Nutr. 2021, 1-17. [CrossRef]

36. Zhang, L.; Li, X.; Ma, B.; Gao, Q.; Du, H.; Han, Y.; Li, Y.; Cao, Y.; Qi, M.; Zhu, Y.; et al. The Tartary Buckwheat Genome Provides Insights into Rutin Biosynthesis and Abiotic Stress Tolerance. Mol. Plant 2017, 10, 1224-1237. [CrossRef]

37. Liu, M.; Ma, Z.; Wang, A.; Zheng, T.; Huang, L.; Sun, W.; Zhang, Y.; Jin, W.; Zhan, J.; Cai, Y.; et al. Genome-Wide Investigation of the Auxin Response Factor Gene Family in Tartary Buckwheat (Fagopyrum tataricum). Int. J. Mol. Sci. 2018, 19, 3526. [CrossRef]

38. Kumar, S.; Stecher, G.; Li, M.; Knyaz, C.; Tamura, K. MEGA X: Molecular Evolutionary Genetics Analysis across Computing Platforms. Mol. Biol. Evol. 2018, 35, 1547-1549. [CrossRef]

39. Edgar, R.C. MUSCLE: Multiple sequence alignment with high accuracy and high throughput. Nucleic Acids Res. 2004, 32, 1792-1797. [CrossRef]

40. Chen, C.; Chen, H.; Zhang, Y.; Thomas, H.R.; Frank, M.H.; He, Y.; Xia, R. TBtools: An Integrative Toolkit Developed for Interactive Analyses of Big Biological Data. Mol. Plant 2020, 13, 1194-1202. [CrossRef]

41. Wang, Y.; Tang, H.; Debarry, J.D.; Tan, X.; Li, J.; Wang, X.; Lee, T.H.; Jin, H.; Marler, B.; Guo, H.; et al. MCScanX: A toolkit for detection and evolutionary analysis of gene synteny and collinearity. Nucleic Acids Res. 2012, 40, e49. [CrossRef]

42. Deng, R.; Zhao, H.; Xiao, Y.; Huang, Y.; Yao, P.; Lei, Y.; Li, C.; Chen, H.; Wu, Q. Cloning, Characterization, and Expression Analysis of Eight Stress-Related NAC Genes in Tartary Buckwheat. Crop. Sci. 2019, 59, 266-279. [CrossRef]

43. Livak, K.J.; Schmittgen, T.D. Analysis of relative gene expression data using real-time quantitative PCR and the $2^{-\Delta \Delta C_{T}}$ Method. Methods 2001, 25, 402-408. [CrossRef]

44. Khaksar, G.; Sangchay, W.; Pinsorn, P.; Sangpong, L.; Sirikantaramas, S. Genome-wide analysis of the Dof gene family in durian reveals fruit ripening-associated and cultivar-dependent Dof transcription factors. Sci. Rep. 2019, 9, 12109. [CrossRef] 
45. Schneeberger, K.; Ossowski, S.; Ott, F.; Klein, J.D.; Wang, X.; Lanz, C.; Smith, L.M.; Cao, J.; Fitz, J.; Warthmann, N.; et al. Reference-guided assembly of four diverse Arabidopsis thaliana genomes. Proc. Natl. Acad. Sci. USA 2011, 108, 10249-10254. [CrossRef]

46. Yu, J.; Hu, S.; Wang, J.; Li, S.; Wong, K.S.G.; Liu, B.; Deng, Y.; Dai, L.; Zhou, Y.; Zhang, X.; et al. A draft sequence of the rice (Oryza sativa ssp. indica) genome. Chin. Sci. Bull. 2001, 46, 1937-1942. [CrossRef]

47. The Tomato Genome Consortium. The tomato genome sequence provides insights into fleshy fruit evolution. Nature 2012, 485, 635-641. [CrossRef] [PubMed]

48. Zhou, Y.; Cheng, Y.; Wan, C.; Li, J.; Yang, Y.; Chen, J. Genome-wide characterization and expression analysis of the Dof gene family related to abiotic stress in watermelon. PeerJ 2020, 8, e8358. [CrossRef]

49. Jeffares, D.C.; Penkett, C.J.; Bahler, J. Rapidly regulated genes are intron poor. Trends Genet. 2008, 24, 375-378. [CrossRef] [PubMed]

50. Cannon, S.B.; Mitra, A.; Baumgarten, A.; Young, N.D.; May, G. The roles of segmental and tandem gene duplication in the evolution of large gene families in Arabidopsis thaliana. BMC Plant Biol. 2004, 4, 10. [CrossRef]

51. Wang, H.; Zhao, S.; Gao, Y.; Yang, J. Characterization of Dof Transcription Factors and Their Responses to Osmotic Stress in Poplar (Populus trichocarpa). PLoS ONE 2017, 12, e0170210. [CrossRef]

52. Li, H.; Dou, L.; Li, W.; Wang, P.; Zhao, Q.; Xi, R.; Pei, X.; Liu, Y.; Ren, Z. Genome-Wide Identification and Expression Analysis of the Dof Transcription Factor Gene Family in Gossypium hirsutum L. Agronomy 2018, 8, 186. [CrossRef]

53. Liu, M.; Wang, X.; Sun, W.; Ma, Z.; Zheng, T.; Huang, L.; Wu, Q.; Tang, Z.; Bu, T.; Li, C.; et al. Genome-wide investigation of the ZF-HD gene family in Tartary buckwheat (Fagopyrum tataricum). BMC Plant Biol. 2019, 19, 248. [CrossRef] [PubMed]

54. Liu, M.; Sun, W.; Ma, Z.; Huang, L.; Wu, Q.; Tang, Z.; Bu, T.; Li, C.; Chen, H. Genome-wide identification of the SPL gene family in Tartary Buckwheat (Fagopyrum tataricum) and expression analysis during fruit development stages. BMC Plant Biol. 2019, 19, 299. [CrossRef] [PubMed]

55. Liu, M.; Ma, Z.; Sun, W.; Huang, L.; Wu, Q.; Tang, Z.; Bu, T.; Li, C.; Chen, H. Genome-wide analysis of the NAC transcription factor family in Tartary buckwheat (Fagopyrum tataricum). BMC Genom. 2019, 20, 113. [CrossRef] [PubMed]

56. Azam, S.M.; Liu, Y.; Rahman, Z.U.; Ali, H.; Yan, C.; Wang, L.; Priyadarshani, S.V.G.N.; Hu, B.; Huang, X.; Xiong, J.; et al Identification, Characterization and Expression Profiles of Dof Transcription Factors in Pineapple (Ananas comosus L). Trop. Plant Biol. 2018, 11, 49-64. [CrossRef]

57. Guo, Y.; Qin, G.; Gu, H.; Qu, L.J. Dof5.6/HCA2, a Dof transcription factor gene, regulates interfascicular cambium formation and vascular tissue development in Arabidopsis. Plant Cell 2009, 21, 3518-3534. [CrossRef] [PubMed]

58. Derbyshire, P.; Drea, S.; Shaw, P.J.; Doonan, J.H.; Dolan, L. Proximal-distal patterns of transcription factor gene expression during Arabidopsis root development. J. Exp. Bot. 2008, 59, 235-245. [CrossRef] [PubMed]

59. Fornara, F.; Panigrahi, K.C.S.; Gissot, L.; Sauerbrunn, N.; Ruhl, M.; Jarillo, J.A.; Coupland, G. Arabidopsis DOF Transcription Factors Act Redundantly to Reduce CONSTANS Expression and Are Essential for a Photoperiodic Flowering Response. Dev. Cell 2009, 17, 75-86. [CrossRef]

60. Sun, W.; Jin, X.; Ma, Z.; Chen, H.; Liu, M. Basic helix-loop-helix (bHLH) gene family in Tartary buckwheat (Fagopyrum tataricum): Genome-wide identification, phylogeny, evolutionary expansion and expression analyses. Int. J. Biol. Macromol. 2020, 155, 1478-1490. [CrossRef]

61. Zhong, R.; Richardson, E.A.; Ye, Z.H. Two NAC domain transcription factors, SND1 and NST1, function redundantly in regulation of secondary wall synthesis in fibers of Arabidopsis. Planta 2007, 225, 1603-1611. [CrossRef] [PubMed]

62. Kim, H.S.; Kim, S.J.; Abbasi, N.; Bressan, R.A.; Yun, D.J.; Yoo, S.D.; Kwon, S.Y.; Choi, S.B. The DOF transcription factor Dof5.1 influences leaf axial patterning by promoting Revoluta transcription in Arabidopsis. Plant J. 2010, 64, 524-535. [CrossRef] [PubMed]

63. Skirycz, A.; Reichelt, M.; Burow, M.; Birkemeyer, C.; Rolcik, J.; Kopka, J.; Zanor, M.I.; Gershenzon, J.; Strnad, M.; Szopa, J.; et al. DOF transcription factor AtDof1.1 (OBP2) is part of a regulatory network controlling glucosinolate biosynthesis in Arabidopsis. Plant J. 2006, 47, 10-24. [CrossRef]

64. Kang, H.G.; Singh, K.B. Characterization of salicylic acid-responsive, Arabidopsis Dof domain proteins: Overexpression of OBP3 leads to growth defects. Plant J. 2000, 21, 329-339. [CrossRef] [PubMed]

65. Zou, H.F.; Zhang, Y.Q.; Wei, W.; Chen, H.W.; Song, Q.X.; Liu, Y.F.; Zhao, M.Y.; Wang, F.; Zhang, B.C.; Lin, Q.; et al. The transcription factor AtDOF4.2 regulates shoot branching and seed coat formation in Arabidopsis. Biochem. J. 2013, 449, 373-388. [CrossRef] [PubMed]

66. Siepel, A.; Arbiza, L. Cis-regulatory elements and human evolution. Curr. Opin. Genet. Dev. 2014, 29, 81-89. [CrossRef] [PubMed]

67. Yu, Y.H.; Bian, L.; Wan, Y.T.; Jiao, Z.L.; Yu, K.K.; Zhang, G.H.; Guo, D.L. Grape (Vitis vinifera) VvDOF3 functions as a transcription activator and enhances powdery mildew resistance. Plant Physiol. Biochem. 2019, 143, 183-189. [CrossRef]

68. Wang, C.M.; Zeng, Z.X.; Su, X.G.; Lakshmanan, P.; Shan, W.; Kuang, J.F.; Lu, W.J.; Chen, J.Y.; Zhao, Y.T. A transcriptional repressor BrDof2.4 regulates protease genes involved in postharvest leaf senescence in Chinese flowering cabbage. Postharvest Biol. Tec. 2021, 181, 111680. [CrossRef]

69. Jin, Z.; Chandrasekaran, U.; Liu, A. Genome-wide analysis of the Dof transcription factors in castor bean (Ricinus communis L.). Genes Genom. 2014, 36, 527-537. [CrossRef] 
70. Song, A.; Gao, T.; Li, P.; Chen, S.; Guan, Z.; Wu, D.; Xin, J.; Fan, Q.; Zhao, K.; Chen, F. Transcriptome-Wide Identification and Expression Profiling of the DOF Transcription Factor Gene Family in Chrysanthemum morifolium. Front. Plant Sci. 2016, 7, 199. [CrossRef] [PubMed]

71. Weirauch, M.T.; Hughes, T.R. Conserved expression without conserved regulatory sequence: The more things change, the more they stay the same. Trends Genet. 2010, 26, 66-74. [CrossRef]

72. Yang, C.; Wang, D.; Zhang, C.; Ye, M.; Kong, N.; Ma, H.; Chen, Q. Comprehensive Analysis and Expression Profiling of PIN, AUX/LAX, and ABCB Auxin Transporter Gene Families in Solanum tuberosum under Phytohormone Stimuli and Abiotic Stresses. Biology 2021, 10, 127. [CrossRef] [PubMed] 